Iwona Sroka*

\title{
RYNEK PO KRYZYSIE. NOWE USŁUGI POST TRANSAKCYJNE W ODPOWIEDZI NA ROZPORZĄDZENIE EMIR
}

\section{Wprowadzenie}

Międzynarodowy kryzys finansowy, za którego początek uważa się upadek amerykańskiego banku Lehman Brothers we wrześniu 2008 r. ${ }^{1}$, był efektem problemów globalnych instytucji finansowych, spowodowanych niekontrolowanym wzrostem rynku derywatów, zwłaszcza z rynku OTC². Rynek OTC (over-the-counter), pozagiełdowy i nieregulowany, praktycznie wymknął się spod kontroli organów nadzorczych, które nie dysponowały narzędziami, aby zmierzyć jego skalę i na czas podjąć odpowiednie kroki ostrożnościowe.

Globalizacja rynków finansowych i międzynarodowe powiązania kapitałowe spowodowały, że prace nad wprowadzeniem rozwiązań mających na celu zniwelowanie negatywnych skutków kryzysu, jak również zapobieganie podobnym perturbacjom w przyszłości, musiały odbyć się na szczeblu ponadnarodowym. We wrześniu 2009 r. przedstawiciele grupy G-20 na szczycie w Pittsburghu przyjęli zalecenia, które zapoczątkowały wiele inicjatyw legislacyjnych na całym świecie. Ich przejawem są m.in. nowe regulacje dotyczące funkcjonowania rynków finansowych na poziomie Unii Europejskiej³.

W obszarze rynku kapitałowego projekty legislacyjne i nowe regulacje obejmują w zasadzie wszystkie aspekty jego funkcjonowania: od instytucji infrastrukturalnych, jak platformy obrotu, centralne depozyty papierów wartościowych i izby

\footnotetext{
* Krajowy Depozyt Papierów Wartościowych.

1 M.K. Singh, S. Thomas, Trade Repositories and their role in the financial marketplace, IGIDR Finance Research Group Technical Report, Indira Gandhi Institute of Development Research, Mumbai 2011. http:// www.igidr.ac.in/FSRR/PDF/201103_traderepositories_technote.pdf

$2 \mathrm{M}$. Carney, Completing the G20 reform agenda for strengthening over-the-counter derivatives markets, "Financial Stability Review" 2013, No. 17, s. 12.

3 K. Lannoo, The New Financial Regulatory Paradigm: A transatlantic perspective, "CEPS Policy Brief" 2013 No. 287, http://ceps.eu/book/new-financial-regulatory-paradigm-transatlantic-perspective
} 
rozliczeniowe, poprzez firmy inwestycyjne, instytucje kredytowe, aż po przedsiębiorstwa (także spoza rynku finansowego).

Tabela 1. Lista wybranych regulacji europejskich w obszarze rynku finansowego

\begin{tabular}{|l|l|}
\hline \multicolumn{1}{|c|}{ Skrót } & \\
\hline AIFMD & Alternative Investment Funds Managers Directive \\
\hline CRD/CRR & Capital Requirements Directive/Capital Requirements Regulation \\
\hline CSDR & Central Securities Depository Regulation \\
\hline EMIR & European Market Infrastructure Regulation \\
\hline MIFID II/MIFIR & Markets in Financial Instruments Directive I//Markets in Financial Instruments Regulation \\
\hline SSR & Short Selling Regulation \\
\hline UCITS V & Undertakings for Collective Investment in Transferable Securities \\
\hline
\end{tabular}

Źródło: Opracowanie własne na podstawie informacji ze strony www.europa.eu

Jak się oczekuje, regulacje te stworzą nowe uwarunkowania dla świadczenia usług finansowych, w tym w obszarze post transakcyjnym. Z jednej strony uporządkują i doprecyzują zasady funkcjonowania podmiotów infrastrukturalnych, z drugiej wprowadzą izby rozliczeniowe typu centralny kontrpartner (CCP - central counterparty), a w dalszej kolejności centralne depozyty papierów wartościowych (CSD - central securities depository), w środowisko konkurencyjne i zdemonopolizowane.

Jednym z najważniejszych aktów prawnych mających wpływ na funkcjonowanie infrastruktury post transakcyjnej jest European Market Infrastructure Regulation (EMIR), czyli Rozporządzenie Parlamentu Europejskiego i Rady (UE) NR 648/2012 $\mathrm{z}$ dnia 4 lipca $2012 \mathrm{r}$. w sprawie instrumentów pochodnych będących przedmiotem obrotu poza rynkiem regulowanym, kontrahentów centralnych i repozytoriów transakcji, który będzie przedmiotem niniejszego artykułu.

\section{Przedmiot i zakres regulacji EMIR}

Rozporządzenie EMIR weszło w życie 16 sierpnia 2012 r., a jego głównym celem jest ograniczenie ryzyka kredytowego, operacyjnego, a także zwiększenie transparentności ekspozycji na transakcje pochodne poprzez zwiększenie wiedzy nadzorców w zakresie skali i typów zawieranych transakcji.

Zgodnie $\mathrm{z}$ art. 1 rozporządzenia, ustanawia ono „wymogi w zakresie usług rozliczeniowych i dwustronnego zarządzania ryzykiem dotyczące kontraktów pochodnych będących przedmiotem obrotu poza rynkiem regulowanym, wymogi w zakresie 
zgłaszania kontraktów dotyczących instrumentów pochodnych oraz jednolite wymogi dotyczące prowadzenia działalności przez kontrahentów centralnych (CCP) i repozytoria transakcji"4.

Uzupełnieniem regulacji EMIR są tzw. rozporządzenia delegowane (regulacyjne standardy techniczne), doprecyzowujące zapisy rozporządzenia.

Warto nadmienić, że samo rozporządzenie nie wprowadza sankcji za jego nieprzestrzeganie, natomiast ustawodawcy krajowi zobligowani zostali do wprowadzenia sankcji za nieprzestrzeganie lub niewłaściwe stosowanie rozporządzenia EMIR przez podmioty objęte jego zakresem.

\section{Podmiotowy zakres rozporządzenia EMIR}

Zgodnie z zapisem art. 1 EMIR „rozporządzenie stosuje się do CCP oraz ich członków rozliczających, kontrahentów finansowych i repozytoriów transakcji. W odniesieniu do kontrahentów niefinansowych i systemów obrotu ma ono zastosowanie, jeśli tak przewidziano". Biorąc pod uwagę zakres niniejszego opracowania, wyróżnić należy dwie podstawowe kategorie podmiotów, których dotyczą zapisy regulacji EMIR. Z jednej strony są to podmioty działające na rynku finansowym zobligowane do centralnego rozliczania określonych klas instrumentów w izbach rozliczeniowych typu CCP oraz zgłaszania informacji o zawieranych kontraktach pochodnych do repozytoriów transakcji, z drugiej zaś to instytucje odpowiedzialne za dostarczanie usług w zakresie rozliczania (izby CCP) oraz podmioty prowadzące repozytoria transakcji.

Rozporządzenie, $\mathrm{w}$ art. 2, definiuje podstawowe instytucje infrastrukturalne, dzięki którym mogą być realizowane postanowienia regulacji - izby rozliczeniowe CCP oraz repozytoria transakcji.

CCP określane jest jako osoba prawna, która działa pomiędzy kontrahentami kontraktów będących w obrocie na co najmniej jednym rynku finansowym, stając się nabywcą dla każdego sprzedawcy i sprzedawcą dla każdego nabywcy. Z kolei „repozytorium transakcji”, wg definicji EMIR, to osoba prawna zajmująca się gromadzeniem i przechowywaniem na szczeblu centralnym danych dotyczących instrumentów pochodnych.

\footnotetext{
4 Dziennik Urzędowy Unii Europejskiej L 201/1 z dnia 27 lipca 2012 r.; http://eur-lex.europa.eu/LexUriServ/LexUriServ.do?uri=OJ:L:2012:201:0001:0059: PL:PDF
} 
Z punktu widzenia właściwego wypełniania zapisów regulacji, istotne jest także określenie zakresu podmiotów podlegających obowiązkom rozporządzenia EMIR. Wyróżnia ono trzy podstawowe kategorie podmiotów:

1. Kontrahenci finansowi (FC) - to kontrahenci instytucjonalni, działający i oferujący na terenie Europejskiego Obszaru Gospodarczego (EOG) usługi finansowe na podstawie właściwych zezwoleń organów nadzoru (szczegółowo wymienieni w rozporządzeniu EMIR) $)^{5}$.

2. Kontrahenci niefinansowi podlegający obowiązkowi rozliczania (NFC +) - czyli kontrahenci niebędący kontrahentami finansowymi w rozumieniu rozporządzenia EMIR, którzy przekroczyli progi rozliczeniowe, nakazujące przekazywanie zawartych przez nich transakcji do rozliczenia przez kontrahenta centralnego (CCP).

3. Kontrahenci niefinansowi niepodlegający obowiązkowi rozliczania (NFC-) - kontrahenci niebędący kontrahentami finansowymi w rozumieniu rozporządzenia EMIR.

Tabela 2. Progi kwotowe obligujące do centralnego rozliczania kontraktów OTC przez podmioty niefinansowe

\begin{tabular}{|l|c|}
\hline \multicolumn{1}{|c|}{ Rodzaj kontraktu } & Próg kwotowy \\
\hline Kredytowe instrumenty pochodne & $1 \mathrm{mld}$ EUR \\
\hline Akcyjne instrumenty pochodne & $1 \mathrm{mld}$ EUR \\
\hline Instrumenty pochodne stopy procentowej & $3 \mathrm{mld}$ EUR \\
\hline Walutowe instrumenty pochodne & $3 \mathrm{mld}$ EUR \\
\hline Pochodne kontrakty towarowe i inne & $3 \mathrm{mld}$ EUR \\
\hline
\end{tabular}

Źródło: Opracowanie własne na podstawie EMIR.

Kontrahenci niefinansowi zajmujący pozycję $\mathrm{w}$ instrumentach pochodnych są zobowiązani do kontrolowania, czy pozycje te nie przekraczają progów kwotowych podanych $\mathrm{w}$ poniższej tabeli, co wiąże się $\mathrm{z}$ obowiązkiem poinformowania o tym fakcie ESMA (European Securities and Market Authority) i właściwego organu

5 Zgodnie z art. 2 rozporządzenia EMIR kontrahenci finansowi oznaczają przedsiębiorstwa inwestycyjne, którym udzielono zezwolenia zgodnie z dyrektywą 2004/39/WE; instytucje kredytowe, którym udzielono zezwolenia zgodnie z dyrektywą 2006/48/WE; zakłady ubezpieczeń, którym udzielono zezwolenia zgodnie z dyrektywą 73/239/EWG; zakłady ubezpieczeń, którym udzielono zezwolenia zgodnie z dyrektywą 2002/83/WE; zakłady reasekuracji, którym udzielono zezwolenia zgodnie z dyrektywą 2005/68/WE; UCITS i odpowiednio ich spółki zarządzające, którym udzielono zezwolenia zgodnie z dyrektywą 2009/65/WE; instytucje pracowniczych programów emerytalnych w rozumieniu art. 6 lit. a) dyrektywy 2003/41/WE oraz alternatywne fundusze inwestycyjne zarządzane przez zarządców alternatywnych funduszy inwestycyjnych, którym udzielono zezwolenia lub które zarejestrowano zgodnie z dyrektywą 2011/61/UE. 
nadzorującego. Podane poniżej progi kwotowe dotyczą średniej pozycji w transakcjach lub kontraktach pochodnych w ciągu 30 dni roboczych. Konsekwencją przekroczenia podanych progów kwotowych jest m.in. obowiązek rozliczania kontraktów OTC przez kontrahenta centralnego, tak samo jak robią to kontrahenci finansowi.

Kontrahenci niefinansowi, którzy przekroczyli powyższe progi kwotowe są od tej chwili określani jako „NFC +”, w przeciwieństwie do pozostałych kontrahentów niefinansowych określanych jako „NFC-”.

\section{Repozytoria transakcji}

Definicja repozytorium określona została w art. 2 regulacji EMIR i przytoczona w poprzedzającym podrozdziale. Z kolei art. 9 EMIR wprowadził obowiązek zgłaszania informacji o zawieranych kontraktach pochodnych do zarejestrowanych lub uznanych zgodnie z rozporządzeniem, repozytoriów transakcji: „,kontrahenci i CCP zapewniają zgłaszanie szczegółowych informacji na temat każdego zawartego przez siebie kontraktu pochodnego oraz na temat wszelkich zmian lub rozwiązania tego kontraktu repozytorium transakcji zarejestrowanemu zgodnie $\mathrm{z}$ art. 55 lub uznanemu zgodnie $\mathrm{z}$ art. 77”'

ESMA prowadzi rejestr repozytoriów transakcji w myśl art. 55 EMIR. Warunkiem kwalifikowania się do uzyskania rejestracji jest posiadanie przez repozytorium transakcji statusu osoby prawnej z siedzibą w Unii i spełnianie wymogów ustanowionych w rozporządzeniu. Zgodnie $\mathrm{z}$ art. 56 repozytorium składa wniosek rejestracyjny w ESMA, która wydaje decyzję o rejestracji repozytorium transakcji. Zgodnie z zapisami rozporządzenia po upływie 90 dni od uprawomocnienia się decyzji ESMA o zarejestrowaniu pierwszego repozytorium ${ }^{6} \mathrm{w}$ życie wchodzi obowiązek raportowy. Nastąpiło to z dniem 12 lutego 2014 r., gdyż z dniem 14 listopada 2013 r. uprawomocniła się decyzja ESMA o rejestracji czterech pierwszych repozytoriów transakcji.

Kontrahenci finansowi i niefinansowi oraz CCP mają obowiązek zgłaszania szczegółowych informacji na temat każdego zawartego przez siebie kontraktu pochodnego oraz na temat wszelkich zmian lub rozwiązania tego kontraktu do repozytorium transakcji. Informacje te mają być przekazywane do repozytorium nie później niż w dniu roboczym następującym po zawarciu, zmianie warunków lub rozwiązaniu kontraktu.

\footnotetext{
6 Komunikat ESMA List of registered trade repositories; http://www.esma.europa.eu/content/List -registered-Trade-Repositories
} 
Tabela 3. Lista zarejestrowanych repozytoriów transakcji (stan na 28.02.2015)

\begin{tabular}{|l|c|}
\hline \multicolumn{1}{|c|}{ Repozytorium } & Data \\
\hline DTCC Derivatives Repository Ltd. & 14.11 .2013 \\
\hline KDPW_TR & 14.11 .2013 \\
\hline Regis-TR S.A. & 14.11 .2013 \\
\hline UnaVista Ltd. & 14.11 .2013 \\
\hline CME Trade Repository Ltd. & 5.12 .2013 \\
\hline ICE Trade Vault Europe Ltd. & 5.12 .2013 \\
\hline
\end{tabular}

Źródło: Opracowanie własne na podstawie danych ESMA.

Obowiązek raportowania dotyczy:

- transakcji zawartych przed 16 sierpnia 2012 r., aktywnych w tym dniu,

- transakcji zawartych 16 sierpnia 2012 r. lub później.

Zgodnie z zapisami EMIR istnieje możliwość delegowania raportowania do innego podmiotu:

- $\mathrm{CCP}$,

- drugiej strony transakcji,

- podmiotu trzeciego.

Pomimo delegowania raportowania, za prawidłowe wykonanie obowiązku raportowego w dalszym ciągu spoczywa na kontrahencie:

- odpowiedzialność za poprawne i terminowe przekazanie raportu,

- odpowiedzialność za merytoryczną poprawność danych,

- odpowiedzialność za uzgodnienie szczegółów kontraktu z drugą stroną transakcji.

\section{Polski rynek: Repozytorium Transakcji w KDPW - KDPW_TR}

Konsekwencją wprowadzenia przez rozporządzenie EMIR obowiązku raportowego dotyczącego zawieranych kontraktów pochodnych było uruchomienie 23 stycznia 2014 r. przez Krajowy Depozyt Papierów Wartościowych repozytorium transakcji - KDPW_TR, funkcjonującego na podstawie Regulaminu repozytorium transakcji. Nowelizacja ustawy o obrocie instrumentami finansowymi ${ }^{7}$, która weszła w życie 4 sierpnia 2012 r. (art. 48 ust. 5a) stanowi, że Krajowy Depozyt Papierów Wartościowych może prowadzić - na zasadach określonych w odrębnym regulaminie - repozytorium

7 Ustawa z dnia 29 lipca 2005 r. o obrocie instrumentami finansowymi, http://isap.sejm.gov.pl/ DetailsServlet?id=WDU20051831538 
transakcji, czyli działalność polegającą na gromadzeniu i przechowywaniu informacji dotyczących transakcji, których przedmiotem są instrumenty finansowe oraz informacje dotyczące tych instrumentów. Wprowadzenie zapisów ustawowych w polskim porządku prawnym usankcjonowało działalność KDPW_TR. Mimo iż KDPW nie był zobligowany do utworzenia repozytorium transakcji, była to jego decyzja biznesowa, mająca na celu oferowanie na polskim rynku komplementarnego pakietu usług post transakcyjnych ${ }^{8}$.

Regulamin KDPW_TR określa w szczególności prawa i obowiązki stron, warunki techniczne, sposób raportowania, typy uczestnictwa, uprawnienia w zakresie dostępu do danych, sposób obsługi certyfikatów dostępowych, opłaty na rzecz KDPW_TR 9 .

KDPW_TR prowadzi rejestr w zakresie następujących klas instrumentów pochodnych, niezależnie od miejsca zawarcia kontraktu (rynek regulowany lub rynek OTC):

- towarowy instrument pochodny $(\mathrm{CO})$,

- kredytowy instrument pochodny (CR),

- walutowy instrument pochodny (CU),

- instrument pochodny na akcje (EQ),

- instrument pochodny na stopę procentową (IR),

- inny instrument pochodny (OT).

W praktyce oznacza to, że KDPW_TR przyjmuje informacje o wszystkich kontraktach pochodnych zawieranych na rynku regulowanym i poza nim.

\section{Izby rozliczeniowe CCP}

Rozporządzenie EMIR w pierwszej kolejności definiuje pojęcie centralnego kontrahenta - CCP (central counterparty) (art. 2), a także określa procedurę udzielania zezwolenia na prowadzenie przez nie działalności i procedury jej udzielenia (art. 14 i 17) oraz ustanawia minimalne wymogi kapitałowe (art. 16). Szczegółowo opisywane są również inne wymogi, jak wymogi organizacyjne, zasady prowadzenia działalności, wymogi ostrożnościowe.

Zgodnie z rozporządzeniem EMIR i aktami wykonawczymi do regulacji, wszystkie działające w Unii Europejskiej izby rozliczeniowe CCP do 15 września 2013 r. miały obowiązek złożyć w krajowym organie nadzoru wniosek autoryzacyjny, potwierdzający iż spełniają one wszelkie wymagania stawiane tym podmiotom $w$ regulacji

8 Chcemy być instytucja pierwszego wyboru, „Parkiet” 7 listopada 2014, s. 2.

9 Regulamin repozytorium transakcji, http://www.kdpw.pl/pl/Repozytorium\%20transakcji\%20wersa\% 20EMIR/Strony/Dokumenty.aspx 
EMIR. Potwierdzeniem wywiązania się danej izby z określonych wymogów jest jej autoryzacja, dokonywana przez krajowy organ nadzoru, po rekomendacji międzynarodowego Kolegium, złożonego m.in. z przedstawicieli banku centralnego oraz wybranych członków organów nadzorczych z innych krajów Unii Europejskiej, a także europejskiego organu nadzoru ESMA.

Tabela 4. Autoryzowane izby CCP w Unii Europejskiej

\begin{tabular}{|l|l|c|}
\hline \multicolumn{1}{|c|}{ CCP } & \multicolumn{1}{|c|}{ Państwo } & Data autoryzacji \\
\hline Nasdaq OMX Clearing AB & Szwecja & 18.03 .2014 \\
\hline European Central Counterparty N.V. & Holandia & 1.04 .2014 \\
\hline KDPW_CCP & Polska & 8.04 .2014 \\
\hline Eurex Clearing AG & Niemcy & 10.04 .2014 \\
\hline Cassa di Compensazione e Garanzia S.p.A. & Włochy & 20.05 .2014 \\
\hline LCH.Clearnet SA & Francja & 22.05 .2014 \\
\hline European Commodity Clearing & Niemcy & 11.06 .2014 \\
\hline LCH.Clearnet Ltd & Wielka Brytania & 12.06 .2014 \\
\hline Keler CCP & Węgry & 4.07 .2014 \\
\hline CME Clearing Europe Ltd & Wielka Brytania & 4.08 .2014 \\
\hline CCP Austria, & Austria & 14.08 .2014 \\
\hline LME Clear Ltd & Wielka Brytania & 3.09 .2014 \\
\hline BME Clearing & Hiszpania & 16.09 .2014 \\
\hline OMIClear - C.C., S.A. & Portugalia & 31.10 .2014 \\
\hline Holland Clearing House B.V. & Holandia & 12.12 .2014 \\
\hline Athens Exchange Clearing House (Athex Clear) & Grecja & 22.01 .2015 \\
\hline
\end{tabular}

Źródło: Opracowanie własne na podstawie danych ESMA.

Właściwy organ nadzoru po udzieleniu izbie rozliczeniowej CCP zezwolenia na rozliczanie danej klasy instrumentów pochodnych będących przedmiotem obrotu poza rynkiem regulowanym niezwłocznie powiadamia o tym fakcie ESMA. W terminie sześciu miesięcy od otrzymania powiadomienia lub od zakończenia procedury uznawania, po przeprowadzeniu konsultacji społecznych oraz po konsultacji z ERRS ${ }^{10}$, a także - w stosownych wypadkach - z właściwymi organami krajów trzecich, ESMA opracowuje i przedkłada Komisji do zatwierdzenia projekt regulacyjnych standardów technicznych określający następujące elementy:

- klasę instrumentów pochodnych będących przedmiotem obrotu poza rynkiem regulowanym, które powinny podlegać obowiązkowi rozliczania,

${ }^{10}$ ERRS - Europejska Rada ds. Ryzyka Systemowego. ERRS jest częścią Europejskiego Systemu Nadzoru Finansowego (ESNF), którego celem jest zapewnienie nadzoru nad systemem finansowym Unii. 
- datę lub daty, od których obowiązek rozliczania staje się skuteczny, w tym każde stopniowe wprowadzanie w odniesieniu do kategorii kontrahentów, do których obowiązek rozliczania ma zastosowanie.

Z własnej inicjatywy, po przeprowadzeniu konsultacji społecznych i konsultacji z ERRS oraz - w stosownych wypadkach - z właściwymi organami państw trzecich, ESMA może samodzielnie zidentyfikować określone klasy instrumentów pochodnych, które powinny podlegać obowiązkowi rozliczania, a na rozliczenie których żaden CCP nie otrzymał jeszcze zezwolenia, oraz powiadamia o nich Komisję Europejską.

\section{Polski rynek: Izba rozliczeniowa KDPW_CCP}

Komisja Nadzoru Finansowego 8 kwietnia 2014 r. dokonała autoryzacji izby rozliczeniowej KDPW_CCP, potwierdzając tym samym, że spełnia ona wszystkie wymagania stawiane tego typu instytucjom przez unijne rozporządzenia EMIR. Proces autoryzacji poprzedzony był ze strony izby licznymi pracami, tak aby spełniała ona wszelkie wymogi określone dla CCP w regulacji EMIR. Były to w szczególności:

- wprowadzenie pojęcia nowacji rozliczeniowej do polskiego porządku prawnego (zmiana ustawy o obrocie instrumentami finansowymi) w celu spełnienia definicji centralnego kontrpartnera przez KDPW_CCP,

- podniesienie kapitału KDPW_CCP (aktualnie $228 \mathrm{mln}$ PLN),

- zmiana kolejności uruchamiania środków w systemie gwarantowania rozliczeń w KDPW_CCP,

- dostosowania systemu zarządzania ryzykiem,

- powołanie w ramach rady nadzorczej Komitetu Audytu oraz Komitetu ds. Wynagrodzeń,

- Powołanie Komitetu ds. Ryzyka,

- wprowadzenie usługi rozliczania derywatów z rynku OTC,

- autoryzacja KDPW_CCP zgodnie z wymogami EMIR (złożenie wniosku 28 czerwca 2013 r., pozytywna decyzja 8 kwietnia 2014 r.).

Od końca 2012 r. KDPW_CCP prowadzi system rozliczeń transakcji w instrumentach pochodnych na rynku OTC obejmujący system gwarantowania płynności rozliczeń. Wraz z wnioskiem autoryzacyjnym izba złożyła listę instrumentów OTC, które będzie rozliczała - są to instrumenty pochodne rozliczane w PLN: swapy walutowe (FX SWAP), transakcje FRA, swapy procentowe jednowalutowe oparte na zagranicznych indeksach stóp (IRS) oraz swapy procentowo-walutowe (CIRS). 
W grudniu 2014 r. KDPW_CCP złożyła w Komisji Nadzoru Finansowego wniosek o rozszerzenie autoryzacji o kolejne instrumenty: IRS, OIS, FRA - denominowane w EUR.

Oprócz realizacji własnych obowiązków raportowania jako CCP, KDPW_CCP przygotowała usługę raportowania kontraktów pochodnych do repozytorium transakcji prowadzonego przez KDPW (KDPW_TR) na zlecenie uczestników rozliczających. Raportowanie może oddelegować uczestnik rozliczający, a za jego pośrednictwem - klienci uczestnika i podmioty zawierające transakcje pochodne na zlecenie klientów uczestnika (brokerzy).

\section{Podsumowanie}

Celem rozporządzenia EMIR jest zwiększenie transparentności rynku oraz redukcja ryzyka kredytowego i systemowego, związanych z zawieraniem i rozliczaniem transakcji pochodnych rynku pozagiełdowego (OTC). Cel ten ma być osiągnięty przez wdrożenie:

- obowiązku rozliczania transakcji pochodnych OTC w izbach rozliczeniowych o statusie centralnego kontrahenta (CCP),

- wymogu raportowania wszystkich transakcji pochodnych do repozytorium transakcji, zarówno z rynku OTC, jak i z rynku regulowanego.

Pierwszy z wymogów ma za zadanie ograniczenie ryzyka niewywiązania się stron transakcji z zawartego kontraktu; drugi - zebranie informacji o rynku instrumentów pochodnych - zarówno regulowanego, jak i OTC. Rozporządzenie ustandaryzowało także poziom świadczenia usług przez izby rozliczeniowe typu CCP, wprowadzając wymóg ich autoryzacji pod określonymi w regulacji wymogami, co należy uznać za pozytywny efekt. $Z$ drugiej zaś strony, standaryzacja nie bierze pod uwagę specyfiki poszczególnych rynków finansowych w krajach UE - te same wymogi, a więc i określony poziom kosztów, dotyczą bowiem zarówno wielkich centrów finansowych, jak Londyn czy Frankfurt, jak i mniejszych rynków, np. Europy Środkowej. Przy jednoczesnej konkurencji na rynku usług CCP, jaką wprowadził EMIR, nierówne wydają się pozycje konkurencyjne poszczególnych izb. Inną kwestią jest fakt, że wciąż trwają prace nad ustaleniem klas instrumentów pochodnych z rynku OTC, które mają podlegać obowiązkowi centralnego rozliczania. Obowiązek rozliczeniowy de facto nie wszedł w życie.

Repozytoria transakcji również generują określony koszt rynkowy, związany m.in. z koniecznością utworzenia takiej instytucji, jak również ponoszenia określonych 
opłat za raportowanie przez podmioty zobligowane. Przy konkurencyjnym rynku i takich samych wymogach formalnych, nieuwzględniających specyfiki poszczególnych rynków finansowych w UE, nie wydaje się, żeby zasady równości mogły zostać zachowane. Kolejnym problemem jest możliwość porównywania danych zbieranych przez poszczególne repozytoria. O ile regulatorzy są gotowi do porównań, to nie dysponują oni pełnym obrazem rynku - cały czas trwają prace nad zwiększeniem spójności i rzetelności danych, której niedostatek wynika m.in. z nieposiadania przez wszystkie podmioty raportujące wymaganego kodu LEI i niskiej świadomości obowiązku raportowego na mniejszych rynkach europejskich.

Oceniając wpływ rozporządzenia na rynek, nie sposób nie dostrzec także dylematów środowiska rynku finansowego. Przedmiotem intensywnych prac ze strony europejskiego regulatora są praktycznie wszystkie aspekty działalności instytucji finansowych w zbliżonym czasie - całkiem realnie mogą zatem wystąpić problemy z synchronizacją i spójnością regulacji oraz przeregulowaniem. Zdaniem regulatorów, bezpieczeństwo systemu finansowego wydaje się jednak ważniejsze niż ewentualne niedociągnięcia spowodowane szybkim tempem wprowadzania zmian regulacyjnych. Kierunkowo nowe regulacje nastawione są na bezpieczeństwo, co odbywa się często kosztem możliwości rozwoju biznesu. Znacząco rośnie zakres nadzoru i autoryzacji, co powoduje wzrost obciążeń i kosztów funkcjonowania instytucji finansowych.

\section{Bibliografia}

Carney M., Completing the G20 reform agenda for strengthening over-the-counter derivatives markets, "Financial Stability Review" 2013, No. 17.

Chcemy być instytucja pierwszego wyboru, „Parkiet” 7 listopada 2014.

ESMA Questions and Answers; Implementation of the Regulation (EU) No 648/2012 on OTC derivatives, central counterparties and trade repositories (EMIR), http://www.esma. europa.eu/system/files/2014297_qa_vii_on_emir_implementation_20_march_14_0.pdf

http://www.esma.europa.eu/page/European-Market-Infrastructure-Regulation-EMIR

Komunikat ESMA List of registered trade repositories, http://www.esma.europa.eu/content/ List-registered-Trade-Repositories

Lannoo K., The New Financial Regulatory Paradigm: A transatlantic perspective, "CEPS Policy Brief” 2013, No. 287, http://ceps.eu/book/new-financial-regulatory-paradigm -transatlantic-perspective

Regulamin repozytorium transakcji http://www.kdpw.pl/pl/Repozytorium\%20transakcji\%20wersa\%20EMIR/Strony/Dokumenty.aspx 
Rozporządzenie Parlamentu Europejskiego i Rady (UE) Nr 648/2012 z dnia 4 lipca 2012 r. $\mathrm{w}$ sprawie instrumentów pochodnych będących przedmiotem obrotu poza rynkiem regulowanym, kontrahentów centralnych i repozytoriów transakcji, Dziennik Urzędowy Unii Europejskiej L 201/1, 27 lipca 2012 r., http://eur-lex.europa.eu/LexUriServ/LexUriServ.do?uri=OJ:L:2012:201:0001:0059: PL:PDF

Singh M.K., Thomas S., Trade Repositories and their role in the financial marketplace, IGIDR Finance Research Group Technical Report, Indira Gandhi Institute of Development Research, Mumbai 2011.

Ustawa z dnia 29 lipca 2005 r. o obrocie instrumentami finansowymi, http://isap.sejm.gov. pl/DetailsServlet?id=WDU20051831538

\section{The Market after the Crisis. New Post-trade Services in Response to EMIR}

The paper discusses the impact of Regulation (EU) No 648/2012 of the European Parliament and of the Council of 4 July 2012 on OTC derivatives, central counterparties and trade repositories on post-trade infrastructure of the financial market. In particular, it focuses on central counterparty (CCP) clearing houses defined in the Regulation, as well as the subjective and objective scope of application of EMIR. The paper also refers to the impact of the Regulation on the Polish market, as well as the measures taken by the local post-trade infrastructure institutions: the Central Securities Depository of Poland (KDPW) and the clearing house KDPW_CCP.

Keywords: EMIR, trade repository, CCP, derivatives, OTC market

\section{Le marché après la crise. Nouveaux services post-marché en réponse à EMIR}

Le document traite de l'impact du Règlement (UE) $n^{\circ}$ 648/2012 du Parlement européen et du Conseil du 4 juillet 2012 sur les produits dérivés de gré à gré, les contreparties centrales et les référentiels centraux sur l'infrastructure post-trade du marché financier. Il met l'accent sur les chambres de compensation de contrepartie centrale définies dans le règlement, ainsi que sur la portée subjective et objective de l'application d'EMIR. Le document fait également référence à l'impact du règlement sur le marché polonais, ainsi que les mesures prises par les institutions locales: le dépositaire central de titres de la Pologne et la chambre de compensation. 
Mots clés: EMIR, le référentiel central, la contrepartie centrale, les dérivés, le marché de gré à gré

\section{Рынок после кризиса. Новые расчетно-клиринговые услуги в ответ на EMIR}

Статья Рынок после кризиса. Новые расчетно-клиринговые услуги в ответ на EMIR обсуждает влияние Регламента (EC) № 648/2012 Европейского Партамента и Совета от 4 июля 2012 года о рынке внебиржевых деривативов, центральных контрагентах и торговых репозиториях на пост-трейдинговую инфраструктуру финансового рынка. В частности, она касается функционирования клиринговых палат, выступающих центральным контрагентом (ССР), торговых репозиториев, а также субъектов и предмета регулирования EMIR. Автор относится к влиянию положений Регламента на польский рынок и к мерам, предпринятым местными институтами пост-трейдинговой инфраструктуры: Национальным депозитарием ценных бумаг Польши $(\mathrm{KDPW})$ и центральным контрагентом KDPW_CCP.

Ключевые слова: EMIR, торговый репозиторий, ССР, производные финансовые инструменты, внебиржевой рынок 
